\title{
Impacto do Projeto Hora de Plantar sobre a sustentabilidade da produção de milho híbrido dos agricultores familiares no Cariri cearense
}

\author{
Impact of Planting Time Project on sustainability of hybrid maize \\ production of family farms in Cariri Ceará
}

\author{
Anderson da Silva Rodrigues ${ }^{1}$, Ahmad Saeed Khan ${ }^{1,2}$, Patrícia Verônica Pinheiro Sales Lima ${ }^{3}$, \\ Eliane Pinheiro de Sousa ${ }^{1}$ (1) \\ ${ }^{1}$ Departamento de Economia, Universidade Regional do Cariri (URCA), Crato (CE), Brasil. E-mails: \\ anderson_rodrigues750@outlook.com; saeed@ufc.br; pinheiroeliane@hotmail.com \\ ${ }^{2}$ Fundação Cearense de Apoio ao Desenvolvimento Científico e Tecnológico (FUNCAP), Fortaleza (CE), Brasil. \\ ${ }^{3}$ Programa de Pós-graduação em Desenvolvimento e Meio Ambiente, Universidade Federal do Ceará (UFC), Fortaleza (CE), \\ Brasil. E-mail: pvpslima@gmail.com
}

Como citar: Rodrigues, A. S., Khan, A. S., Lima, P. V. P. S., \& Sousa, E. P. (2020). Impacto do Projeto Hora de Plantar sobre a sustentabilidade da produção de milho híbrido dos agricultores familiares no Cariri cearense. Revista de Economia e Sociologia Rural, 58(2), e197622. https://doi.org/10.1590/1806-9479.2020.197622

Resumo: Esta pesquisa avalia o impacto do Projeto Hora de Plantar sobre a sustentabilidade agrícola dos agricultores familiares de milho híbrido da Microrregião do Cariri mediante a construção de um Índice de Sustentabilidade da Produção (ISP), composto pelas dimensões econômica, ambiental e tecnológica. Utilizaram-se dados de origem primária, obtidos mediante 210 questionários semiestruturados, sendo 90 para produtores beneficiários e 120 para não beneficiários do programa. A comparação entre grupo tratamento (beneficiários) e controle (não beneficiários) foi realizada por meio da aplicação da técnica de Propensity Score Matching com balanceamento por entropia. Os resultados revelam que o Índice de Sustentabilidade da Produção entre os beneficiários é significativamente superior ao dos não beneficiários. Em relação aos componentes do ISP, oS beneficiários apresentaram superioridade estatisticamente significativa nos índices das dimensões econômica e tecnológica, porém os dois grupos de agricultores apresentaram estimativas não estatisticamente significantes para a dimensão ambiental. Ademais, recomenda-se a ampliação dos serviços de assistência técnica e extensão rural visando estimular a adoção de práticas agrícolas sustentáveis.

Palavras-chave: sustentabilidade agrícola, avaliação de impacto, milho híbrido.

\begin{abstract}
The main objective of this study was to evaluate the impact of "Projeto Hora de Plantar" (time to plant) on agricultural sustainability of family farms of hybrid maize in the Microrregion of Cariri. For this purpose, we constructed the Production Sustainability Index (ISP), incorporating economic, environmental, and technological aspects. We obtained the primary data through the application of 90 semi-structured questionnaires to the beneficiaries and 120 to non-beneficiaries of the program, totaling 210 questionnaires. We use the Propensity Score Matching technique with Entropy Balancing for the comparison between treated (beneficiaries) and control (non-beneficiaries). The results showed that the production sustainability index of beneficiaries is significantly higher than in non-beneficiaries. The economic and technological components of ISP of beneficiaries were significantly higher than those of non-beneficiaries of the project; however, the two groups of farmers presented non-statistically significant estimates for the environmental dimension. Also, it is recommended the extension of technical assistance and rural extension services to stimulate the adoption of sustainable agricultural practices.
\end{abstract}

Keywords: agricultural sustainability, impact evaluation, hybrid maize. 


\section{Introdução}

O setor agrícola é fortemente dependente de políticas públicas em virtude dos riscos de oscilação da produção e dos preços que afetam diretamente a renda dos produtores (Empresa Brasileira de Pesquisa Agropecuária, 2018). A partir dos anos 1990, houve no País importante reorientação nas políticas agrícolas. Tal processo foi influenciado pela maior atenção à agricultura familiar, pela incorporação da questão ecológica ao discurso das políticas agrícolas e pelo fortalecimento de uma nova visão de gestão pública com o reconhecimento da necessidade de avaliação das ações governamentais. Para Grisa \& Schneider (2014) e Instituto Brasileiro de Geografia e Estatística (2009), a maior atenção estatal ao produtor familiar é oriunda tanto da pressão dos movimentos sociais ligados às causas camponesas quanto do reconhecimento da importância do segmento familiar enquanto categoria econômica.

Com a crise econômica dos anos 1970, juntamente com a crise do modelo de intervenção social nas economias desenvolvidas, o Estado moderno passa por forte questionamento tanto nas suas funções quanto na eficácia das ações intervencionistas na realidade social. Esse questionamento levou à percepção de que a compreensão dos elementos determinantes do sucesso ou fracasso das políticas públicas passa a ser primordial para o aumento da eficiência de ações posteriores. Assim, a avaliação de políticas públicas ganha destaque como elemento estratégico da ação estatal (Trevisan \& Van Bellen, 2008).

Paralelamente, a percepção da crise ambiental e a ascensão da questão ecológica ao discurso político, nos anos 1980 e 1990, impactaram na forma de atuação das diferentes esferas públicas, promovendo uma reorientação das políticas públicas, que passam a incorporar, em seus objetivos, ações de promoção da sustentabilidade (Bursztyn \& Bursztyn, 2010; Ferreira, 1998). Essa nova conjuntura permite atribuir um potencial impacto das políticas públicas sobre a adoção de técnicas que influenciam o meio ambiente (HălbacCotoară-Zamfir et al., 2019) e, consequentemente, a sustentabilidade dos sistemas agrícolas.

No Ceará, a preocupação com a questão sobre a sustentabilidade da atividade agrícola tem se materializado através dos Planos de Desenvolvimento Rural Sustentável após 1995. Um dos programas estaduais de apoio à agricultura familiar de maior alcance é o Projeto Hora de Plantar (PHP), que consiste na distribuição subsidiada de sementes híbridas geneticamente selecionadas, de modo a garantir maior produtividade e a necessária rusticidade para adaptação às condições edafoclimáticas nordestinas (Santana et al., 1999). Este projeto está presente em 182 dos 184 municípios cearenses e atende a mais de 130 mil produtores.

A cultura do milho, em virtude da ampla utilização tanto para alimentação humana quanto animal e de sua fácil adaptabilidade aos diversos tipos de solo e clima existentes no Ceará, ocupa posição de destaque na agricultura estadual, correspondendo, no ano de 2014, a $17,24 \%$ do valor da produção das lavouras permanentes e $46,8 \%$ do valor da produção de grãos produzidos no estado do Ceará (Instituto Brasileiro de Geografia e Estatística, 2015). Ressalta-se que tal importância é maior para o segmento familiar, no qual o milho, cultivado, em sua maioria, em sistema consorciado com outras culturas, sobretudo, o feijão, está presente em cerca de $60 \%$ das propriedades com área até 20 ha (Cuenca et al., 2005).

Deste modo, em virtude da relevância econômica da produção de milho, tanto para o estado do Ceará quanto para a agricultura familiar, do alcance do Projeto Hora de Plantar e da escassez de estudos em relação ao tema, torna-se necessária a investigação que possibilite a avaliação desta política pública, permitindo identificar a adequação dos resultados obtidos aos objetivos inicialmente formulados pelo Projeto. Neste sentido, o objetivo deste artigo é avaliar o impacto deste projeto sobre a sustentabilidade agrícola da produção de milho híbrido dos agricultores familiares na microrregião cearense do Cariri.

Além desta introdução, o restante do artigo está estruturado em seis seções. A segunda seção apresenta uma breve revisão da literatura sobre sustentabilidade agrícola. A terceira seção apresenta de forma resumida o Projeto Hora de Plantar. Na quarta seção, fundamenta-se a avaliação de impacto em políticas públicas via técnicas de Propensity Score Matching com balanceamento por entropia. Na quinta seção, detalham-se a metodologia empregada e os dados 
utilizados neste estudo. A seção 6 analisa os resultados dos níveis de sustentabilidade entre os grupos. Na última seção, são mostradas as considerações finais do artigo.

\title{
2. Sustentabilidade agrícola: conceito, desafios e mensuração
}

O aumento da demanda por alimentos produziu transformações radicais no campo. A primeira Revolução Verde, nas décadas de 1960 e 1970, promoveu significativos aumentos na produtividade agrícola com a incorporação de tecnologias baseadas na mecanização, a seleção genética de variedades mais produtivas e a utilização de insumos oriundos das indústrias químicas e petroquímica com efeitos sobre a contaminação de água e solo, exclusão da agricultura familiar do processo de modernização, erosão, perda de diversidade genética e maior dependência de energia fóssil (Leff, 2009; Rodrigues, 2009).

A utilização massiva de tecnologias inadequadas do ponto de vista ambiental representa desafios à construção de uma agricultura assentada em bases sustentáveis. Segundo Gliessman (2000, p. 600-601), a agricultura sustentável pode ser concebida como:

\begin{abstract}
Aquela que reconhece a natureza sistêmica da produção de alimentos, forragens e fibras equilibrando, com equidade, preocupações relacionadas à saúde ambiental, justiça social e viabilidade econômica, entre os diferentes setores da população, incluindo distintos povos e diferentes gerações.
\end{abstract}

Para Altieri (2000), a convergência para práticas agrícolas sustentáveis pressupõe inversão de uma ótica otimizadora da produção para uma ótica otimizadora do sistema como um todo, o que exige mudanças no direcionamento da pesquisa científica, com ênfase na busca de sistemas produtivos que privilegiem práticas de rotação de cultivos, pesquisa de fontes alternativas de nutrição, novas estratégias de gestão, implementação de estratégias integradas de controle de pragas e plantas daninhas, e sistemas alternativos de pecuária (Almeida, 1998).

Assim, diversos autores apontam para o importante papel da inovação tecnológica na concretização da sustentabilidade agrícola, ao permitir a exploração mais racional dos recursos naturais e potencializar ganhos de produtividade capazes de manter um adequado padrão de vida ao produtor rural (Caporal \& Costabeber, 2004; Labrador Moreno \& Altieri, 1994). Embora haja técnicas produtivas de redução do impacto ambiental da atividade agrícola, é necessário destacar que as práticas conservacionistas são pouco adotadas no País, em que somente $10,4 \%$ dos produtores nacionais realizam plantio direto e $13,6 \%$ ainda mantêm a queimada como prática de manejo do solo, e 32,8\% utilizam método de adubação, sendo que $78,2 \%$ representados por fertilizantes químicos e apenas $45 \%$ empregam adubação orgânica (Instituto Brasileiro de Geografia e Estatística, 2009; Sambuichi et al., 2012).

Para que se avance em direção à sustentabilidade agrícola, é necessária a criação de formas de mensuração do processo, de modo a permitir identificar avanços, estrangulamentos e perspectivas de atuação. A mensuração da sustentabilidade agrícola representa relevante desafio teórico-metodológico em virtude da amplitude conceitual da sustentabilidade. Assim, apesar dos esforços de diversos organismos internacionais, instituições de pesquisa e acadêmicos, ainda não se obteve consenso sobre quais indicadores e metodologias a serem utilizados para se aferir a sustentabilidade agrícola tanto em escala nacional quanto local (Hayati et al., 2011; Olde et al., 2017).

Em nível nacional, podem-se citar estudos que mensuraram a sustentabilidade agrícola, considerando as dimensões econômica, social, ambiental e político-institucional (Barreto et al., 2005; Damasceno et al., 2011).

Além das dimensões econômica, social e ambiental, outros estudos têm inserido indicadores de caráter técnico-produtivo, relacionados principalmente ao manejo adequado do cultivo. Neste sentido, o manejo correto do solo, a aplicação adequada de defensivos agrícolas e o uso racional da fertilização química são elementos que contribuem para o uso racional dos recursos naturais e, portanto, para a dimensão ambiental (Cruz et al., 2008; Lopes, 2001; Santos \& Cândido, 2013). Tais indicadores revestem-se de especial importância 
em avaliações de sustentabilidade de sistemas agrícolas, dado o papel dos agricultores na manutenção dos serviços ambientais (Bertocchi et al., 2016).

\section{O Projeto Hora de Plantar}

O Projeto Hora de Plantar foi estruturado a partir do programa denominado Arrancada da Produção, lançado em 1987, e consiste na distribuição subsidiada de sementes geneticamente selecionadas de modo a garantir maior produtividade e a necessária rusticidade para adaptação às condições edafoclimáticas nordestinas. Existem cadastrados de modo informatizado na Secretaria de Desenvolvimento Agrário do Ceará (DAS) cerca de 250 mil agricultores(as) familiares. O Programa possui elevada abrangência, estando presente em 182 dos 184 municípios cearenses, ficando de fora apenas Fortaleza e Eusébio, que não possuem zona rural. Além da distribuição de sementes de culturas tradicionais, como milho híbrido, milho variedade, feijão-caupi e feijão phaseolus, o programa passou a incentivar e distribuir mudas enxertadas de cajueiro-anão precoce, manivas de mandioca, raquetes de palma forrageira e mudas de espécies nativas e exóticas, para recuperação de áreas degradadas e de matas ciliares (Ceará, 2015).

O Projeto Hora de Plantar tem como objetivo geral “[...] fortalecer a agricultura familiar, utilizando sementes e mudas de elevado potencial genético que propiciem o aumento da produtividade das culturas e melhorem o nível de renda dos(as) beneficiários(as)" (Ceará, 2015, p. 15). Como objetivos específicos, o projeto prevê ainda:

i) substituir o plantio de grãos por sementes e mudas de alta qualidade; ii) incentivar os beneficiários do projeto a adotarem Práticas Agrícolas de Convivência com o Semiárido; iii) contribuir para a implantação de áreas de reserva alimentar estratégica para os rebanhos bovinos, ovinos e caprinos, usando-se sorgo e palma forrageira; iv) apoiar e incentivar o florestamento e reflorestamento através da distribuição de espécies vegetais nativas e exóticas (Ceará, 2015, p. 15-16).

O Projeto Hora de Plantar tem como público-alvo o(a) agricultor(a) familiar ${ }^{1}$ (proprietário, parceiro, posseiro, meeiro ou arrendatário), o(a) qual recebe sementes e/ou mudas para o plantio de até 10 hectares, dependendo da cultura. No caso do milho híbrido, até cinco hectares.

\section{Estimação do impacto de políticas públicas: as técnicas de Propensity Score Matching e Entropy Balancing}

A questão central e o desafio de uma avaliação de impactos é estabelecer uma relação causal entre a política pública e os resultados obtidos, isolando o efeito de quaisquer outros fatores externos que poderiam explicar os resultados observados. Em termos estatísticos, equivale a verificar as diferenças das médias das variáveis relevantes entre o grupo experimental (que recebe o "tratamento") e o grupo controle. Porém, Rosenbaum \& Rubin (1983) enfatizam que, em amostras não aleatórias, as estimativas amostrais seriam enviesadas, inviabilizando qualquer inferência. Isto ocorre, porque, na maioria das vezes, não é possível investigar o mesmo indivíduo antes e após o tratamento. Outro problema apontado por Attanasio et al. (2005) advém da comparação de indivíduos com características distintas, em que a diferença de resultados entre os dois grupos não seria causada pelo tratamento, mas poderia estar correlacionada à diferença pré-programa entre os indivíduos. Neste caso, a solução reside em investigar o efeito do "tratamento" comparando indivíduos com características observáveis, a priori, semelhantes.

Duarte et al. (2009) enfatizam que o problema deste método é que quanto maior o número de características avaliadas, maior será o número de observações para se proceder ao pareamento entre os grupos tratamento e controle. Para contornar este problema, Rosenbaum \& Rubin (1983) propõem que, em vez de se adotarem as características

\footnotetext{
1 É necessário que o produtor tenha o Documento de Aptidão ao Pronaf (DAP) para a inscrição no projeto. A perda da
} condição de agricultor familiar ocasiona a exclusão automática do projeto (Ceará, 2015). 
observáveis $\left(\mathrm{X}_{\mathrm{i}}\right)$, sejam utilizadas probabilidades de um indivíduo ser beneficiado por uma política pública em função das características observadas $\mathrm{p}\left(\mathrm{X}_{\mathrm{i}}\right)$. Tais autores denominaram esta função de probabilidade como propensity score ou escore de propensão.

Assim, seja T uma variável dummy que assume valor 1 para o indivíduo que recebe o tratamento e valor 0 para o indivíduo não tratado, e X um vetor de características observáveis. Assim, o propensity score pode ser definido pela Equação 1 como:

$p(X)=\operatorname{Pr}(T=l \mid X)=E(T \mid X)$

Uma condição adicional nomeada como condição de balanceamento (balancing condition) afirma que a função escore de propensão é um balanced score, de forma que o vetor $X$ é ortogonal ao vetor de Tratamento $(T)$ condicional a $p(x)$, assim:

$X \perp T \mid p(X)$

A validade do modelo de PSM está condicionada às duas condições ou hipóteses: a) independência condicional; b) existência de suporte comum ou sobreposição significativa dos escores de propensão da amostra de beneficiários e não beneficiários (Rosenbaum \& Rubin, 1983).

O primeiro pressuposto afirma que, para um dado conjunto $X$ de covariáveis observáveis não afetadas pelo tratamento, os resultados potenciais $(Y)$ são independentes da designação do tratamento (T). Se $Y_{1}$ representa o resultado para beneficiários e $Y_{0}$ o resultado para não beneficiários, então a independência condicional implica:

$\left(Y_{1}, Y_{0}\right) \perp T \mid X$

E, pela condição de balanceamento, descrita na Equação 1, decorre que:

$\left(Y_{l}, Y_{0}\right) \perp T_{i} \mid p(X)$

Este pressuposto implica que a escolha de beneficiários para participação do programa é baseada inteiramente em características observadas (Rosenbaum \& Rubin, 1983). É importante ressaltar que independência condicional representa uma hipótese forte e não é um critério testável diretamente, dependendo de características específicas do programa em si. Caso as características não observáveis determinem a inserção no programa, o pressuposto é violado e o método PSM não é apropriado (Khandker et al., 2010).

O segundo pressuposto implica que as distribuições de probabilidade dos escores de propensão dos dois grupos se sobreponham em grande parte (Heckman et al., 1999). Assim, em termos formais, para cada valor de X, existe uma probabilidade positiva para tratados e não tratados, de modo que:

$0<\operatorname{Pr}(T=1 \mid X)<1$

Rosenbaum \& Rubin (1983) mostram que se a exposição ao tratamento é aleatória para o vetor $X$, também será aleatória para uma variável unidimensional $p(X)$. Como resultado, dado um conjunto de indivíduos denotados por $\mathrm{i}$, se o propensity score $\mathrm{p}\left(\mathrm{X}_{\mathrm{i}}\right)$ é conhecido, então o efeito médio do tratamento sobre os tratados (ATT - Average effect of Treatment on Treated) pode ser estimado da seguinte forma:

$A T T=E\left(Y_{1} \mid T=1\right)-E\left(Y_{0} \mid T=1\right)$ 
Da condição de independência condicional (CIA), decorre que o viés de seleção é zero, o que implica que ${ }^{2}$ :

$$
E\left(Y_{0} \mid T=1, X\right)=E\left(Y_{0} \mid T=0, X\right)=E\left(Y_{0} \mid T=0, p(X)\right)
$$

Assim, utilizando as leis das Expectativas Interadas, a Equação 5 pode ser reescrita como:

$$
A T T=E_{p(X) \mid T=1}\left[E\left(Y_{l} \mid T=1, p(X)\right)-E\left(Y_{01} \mid T=0, p(X)\right)\right]
$$

Nos anos recentes, o pareamento por escore de propensão (Propensity Score Matching) tornou-se um dos métodos mais utilizados para a avaliação do efeito causal em "tratamento" nas mais diversas áreas, incluindo a avaliação de políticas públicas. Porém, há de se considerar que este método, conforme apresentado nas Equações 3 e 4, é dependente do balanceamento das covariáveis entre grupos tratamento e controle. Assim, a má especificação na estimação dos escores de propensão pode aumentar o viés nas estimativas do efeito do tratamento, sendo que tal problema é comum nas técnicas de pareamento por PSM e distância de Mahalanobis (Diamond \& Sekhon, 2013).

Hainmueller (2012) argumenta, ainda, que métodos de pré-processamento dos dados - como é o caso do pareamento por escore de propensão - apenas alcançam um balanceamento assintótico das variáveis. Assim, propõe o método de Entropy Balancing (ou balanceamento por entropia) como alternativa metodológica a ser utilizada no pré-processamento dos dados. Duarte (2017) enfatiza que esta técnica representa uma generalização da abordagem de Hirano et al. (2003), que constroem um contrafactual a partir da ponderação das observações do grupo controle utilizando como peso o inverso do escore de propensão, conforme Equação 9 descrita a seguir:

$$
E \overline{\left(Y_{0} \mid T=1\right)}=\frac{\sum_{\{i \mid D=0\}} Y_{i} d_{i}}{\sum_{\{i \mid D=0\}} d_{i}}
$$

Em que: $d_{i}=\frac{\hat{p}\left(X_{i}\right)}{1-\hat{p}\left(X_{i}\right)}$ e $\hat{p}\left(X_{i}\right)$ representa a estimativa para o escore de propensão. O balanceamento por entropia parte da estimação do contrafactual mediante o seguinte esquema de ponderação:

$$
E \widehat{\left(Y_{0} \mid T=1\right)}=\frac{\sum_{\{i \mid D=0\}} Y_{i} w_{i}}{\sum_{\{i \mid D=0\}} w_{i}}
$$

Em que o vetor de pesos $w_{i}$ é obtido por meio do seguinte problema de otimização:

$$
\min _{w_{i}} H(w)=\sum_{\{i \mid D=0\}} w_{i} \log \left(\frac{w_{i}}{q_{i}}\right)
$$

Sujeito às restrições de equilíbrio e normalidade:

$$
\sum_{\{i \mid D=0\}} w_{i} c_{r i}\left(X_{i}\right)=m_{r} \operatorname{com} r \epsilon 1, \ldots, R
$$

\footnotetext{
2 Para demonstração, ver Rosenbaum \& Rubin (1983) e Imbens (2000).
} 
$\sum_{\{i \mid D=0\}} w_{i}=1$

$w_{i} \geq 0$ paratodoi,tal que $T=0$,

A Equação 11 explicita o problema da minimização da função de perda $H(w)$ que representa uma distância métrica de divergência de entropia definida em Kullback (1959); $q_{i}$ é o peso base (com $q_{i} \geq 0 \forall i$ em $D=0$ e $\left.\sum_{i \mid D=0} q i=l\right) ; c_{r i}\left(X_{i}\right)$ descreve um conjunto de R restrições de equilíbrio impostas aos momentos das covariáveis no grupo de controle. Para cada covariável, especifica-se um conjunto de restrições de pareamento para equilibrar os momentos (média, variância e assimetria) das covariáveis entre grupos tratamento e controle. Assim, este esquema de reponderação permite obter um vetor de pesos a ser aplicado às observações do grupo controle de modo a igualar os momentos amostrais das covariáveis entre grupo tratamento e grupo controle reponderado.

\section{Metodologia}

\subsection{Caracterização da área geográfica de estudo}

A área de estudo foi a Microrregião do Cariri no estado do Ceará. Segundo o Instituto de Pesquisa e Estratégia Econômica do Ceará (2010), esta região é composta por oito municípios: Barbalha, Crato, Jardim, Juazeiro do Norte, Missão Velha, Nova Olinda, Porteiras e Santana do Cariri, conforme ilustrado na Figura 1. Localiza-se ao sul do estado do Ceará, fazendo divisa com o estado de Pernambuco, abrange uma área de 4.115,82 $\mathrm{km}^{2}$, onde vivem cerca de 534 mil habitantes, sendo $19,84 \%$ no meio rural e $80,16 \%$ no perímetro urbano.

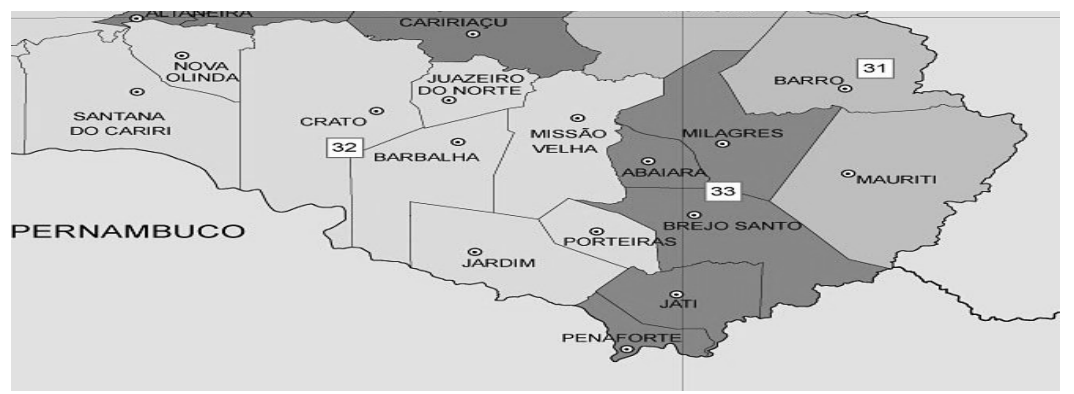

Figura 1 - Área em tonalidade mais clara (32) corresponde aos oito municípios que compõem a Microrregião do Cariri, Ceará. Fonte: Adaptado de Instituto de Pesquisa e Estratégia Econômica do Ceará (2010).

A escolha desta microrregião pode ser atribuída à própria história do Projeto Hora de Plantar, em que o Cariri foi a primeira região a receber as sementes de milho híbrido, em 1999 (Silva, 2005), e devido à importância significativa do plantio de milho para a região. Conforme dados do Sistema HPNet ${ }^{3}$ (Ceará, 2016), foram distribuídas, em 2015, para tal região, 195 toneladas de milho híbrido, correspondentes a 8,8\% das sementes desta cultura distribuídas no estado.

\subsection{Fonte dos dados e procedimentos de determinação da amostra}

Neste estudo, foram utilizados dados primários coletados em fevereiro de 2016, mediante aplicação de 210 questionários semiestruturados, sendo 90 para produtores beneficiados com distribuição de sementes de milho híbrido do Projeto Hora de Plantar

3 O acesso aos dados do sistema HPNet não se dá de forma aberta. Os dados deste artigo foram obtidos via solicitação à Secretaria de Desenvolvimento Agrário do Estado do Ceará com base na Lei n. 15.175/2012 (Lei Estadual de Acesso à Informação). 
(grupo tratamento) e 120 para produtores de milho - não híbrido - não beneficiados pelo programa (grupo controle). O número maior de questionários para o grupo controle segue orientação da literatura em virtude da possibilidade de descarte de observações nos possíveis pareamentos (Passos, 2014). Para a determinação da amostra mínima do grupo de beneficiários, seguiu-se a metodologia proposta por Cochran (1985), para população finita e amostragem aleatória simples, tendo como base a Fórmula 15:

$n=\frac{\left(Z^{2} \cdot \hat{p} \cdot \hat{q} \cdot N\right)}{\left[d^{2} \cdot(N-1)+Z^{2} \cdot \hat{p} \cdot \hat{q}\right]}$

Em que:

$\mathrm{n}=$ tamanho inicial da amostra;

$\mathrm{Z}=$ abscissa da distribuição normal-padrão;

$\hat{p}=$ proporção adotada;

$\hat{q}=$ complemento de $\hat{p}$;

$\mathrm{d}=$ erro de estimação;

$\mathrm{N}=$ tamanho da população.

Em virtude do significativo déficit hídrico no ano de 2015 (Fundação Cearense de Meteorologia e Recursos Hídricos, 2015), com possíveis distorções nos resultados da pesquisa, optou-se por concentrar a amostra nos municípios menos afetados. Assim, foram selecionados os municípios de Barbalha, Santana do Cariri e Nova Olinda, em virtude de os agricultores destes municípios não terem recebido seguro Garantia Safra, sendo isto um indicativo de menores perdas na produção ${ }^{4}$. Neste sentido, o número total de beneficiários nos três municípios é de 1.648 produtores.

A estimação dos valores para as proporções de beneficiários e não beneficiários (valores dos parâmetros p e q) foi obtida por amostra piloto nas localidades de Santana (Barbalha), Araporanga (Santana do Cariri) e Triunfo (Nova Olinda). Tais localidades correspondem àquelas com significativo contingente de produtores de milho. A identificação dos não beneficiários nestas localidades foi efetuada por meio das respectivas associações de produtores. Identificados os não beneficiários, procedeu-se ao cálculo das proporções deste grupo em relação aos beneficiários (cuja relação consta em cadastro na Ematerce), obtendo o valor de $\mathrm{p}$ igual a 90,3\% (proporção de beneficiários) e q igual a 9,7\%. Tais valores determinaram uma amostra mínima de 89 produtores beneficiários, considerando-se um erro de $5 \%$ (valor de $d=0,05$ ).

\subsection{Procedimentos para a construção do Índice de Sustentabilidade da Produção}

Dada a característica multidimensional da sustentabilidade agrícola, optou-se, neste trabalho, por abordar esta questão a partir das dimensões econômica, ambiental e tecnológica. Determinou-se o Índice de Sustentabilidade da Produção (ISP), que consiste na média aritmética dos escores obtidos de três índices que abordam as seguintes dimensões citadas: Índice de Contribuição Econômica (ICE), Índice de Gestão Ambiental da Propriedade (IGAP) e Índice de Adequação Tecnológica da Produção (IATP).

Cada índice, por sua vez, é formado a partir de um conjunto de indicadores assumidos aqui como direcionadores úteis na avaliação da sustentabilidade de sistemas agrícolas em escala local (Zhang et al., 2018). Apesar de possuírem número diverso de variáveis, optou-se por estabelecer pesos iguais entre os indicadores na composição do respectivo índice. Assim, o valor do p-ésimo índice e a contribuição do q-ésimo indicador foram calculados, respectivamente, pelas Equações 16 e 17:

\footnotetext{
${ }^{4}$ Segundo informações dos gerentes locais da Ematerce, o seguro safra beneficia os produtores cadastrados com área superior a 0,6 dos municípios afetados pela estiagem, cuja perda média da produção agrícola supere 50\%.
} 
$I_{p}=\frac{1}{S} \sum_{q=1}^{s} C_{q}$

$C_{q}=\frac{1}{M} \sum_{j=1}^{m}\left[\frac{1}{N}\left(\sum_{i=1}^{n} \frac{E_{i j}}{\operatorname{Emax}_{i}}\right)\right]$

Em que:

Cq representa a contribuição do $q$-ésimo indicador no $p$-ésimo índice dos agricultores familiares;

$E_{i j}$, escore da i-ésima variável do q-ésimo indicador obtida pelo j-ésimo agricultor familiar; $E_{m a x}$, escore máximo da $i$-ésima variável do $q$-ésimo indicador;

$i=1, \ldots, n$ (variáveis que compõem o indicador " $q$ ");

$j=1, \ldots, m$ (agricultores familiares);

$q=1, \ldots s$ (número de indicadores que compõem o $p$-ésimo índice).

As variáveis utilizadas na composição dos índices baseiam-se nos estudos de Passos

(2014) e Silva (2005) com as adaptações pertinentes (Quadro 1).

Quadro 1 - Definição dos índices, indicadores e variáveis utilizados no ICE, IGAP e IATP

\begin{tabular}{|c|c|c|}
\hline Índices & Indicadores & Variáveis \\
\hline ICE & $\begin{array}{l}\text { Margem bruta anual } \\
\text { com a cultura do milho } \\
\text { (MBAEC) }\end{array}$ & $\begin{array}{l}\text { Índice para a margem bruta por hectare com a cultura do } \\
\text { milho ajustada para uma escala proporcional, sendo um para } \\
\text { o maior valor e zero para o menor valor. }\end{array}$ \\
\hline \multirow{9}{*}{ IGAP } & $\begin{array}{l}\text { Indicador de Práticas } \\
\text { Ambientais de Preparo } \\
\text { do Solo (IPAPS) }\end{array}$ & $\begin{array}{l}\text { Usa prática de desmatamento }(1=\operatorname{sim}, 0=\text { não }) / q u e i m a d a \\
(0=\operatorname{sim} ; 1=\text { não }) .\end{array}$ \\
\hline & $\begin{array}{l}\text { Indicador de Práticas } \\
\text { de Plantio e Adubação } \\
\text { (IPPA) }\end{array}$ & $\begin{array}{l}\text { Utiliza curva de nível ou terraço, plantio direto, rotação de } \\
\text { culturas, esterco, fertilizante químico, adubação verde, } \\
\text { compostagem ou biofertilizante ( } 1=\operatorname{sim}, 0 \text { = não). }\end{array}$ \\
\hline & $\begin{array}{l}\text { Indicador de Práticas } \\
\text { de Pós-Plantio (IPPP) }\end{array}$ & Não faz capina = 0, usa herbicida = 1, faz capina manual = 2 . \\
\hline & \multirow{2}{*}{$\begin{array}{l}\text { Indicador de Práticas } \\
\text { de Controle de Pragas } \\
\text { (IPCP) }\end{array}$} & $\begin{array}{l}\text { Métodos de combate de pragas: controle químico = } 0 \text {, não usa } \\
\text { nada }=1 \text {, controle biológico }=2 \text {. }\end{array}$ \\
\hline & & $\begin{array}{l}\text { Frequência de uso do controle químico: } 0 \text { = mais de } 2 \text { vezes; } \\
1=2 \text { vezes; } 2 \text { = uma vez. }\end{array}$ \\
\hline & \multirow{3}{*}{$\begin{array}{l}\text { Indicador de Gestão de } \\
\text { Resíduos Sólidos (IGRS) }\end{array}$} & Reutiliza resíduos orgânicos: 1 = sim, 0 = não. \\
\hline & & $\begin{array}{l}\text { Faz reaproveitamento de resíduos inorgânicos (embalagens } \\
\text { em geral): } 1 \text { = sim, } 0 \text { = não. }\end{array}$ \\
\hline & & $\begin{array}{l}\text { Descarte irregular de embalagens de produtos tóxicos: } \\
1 \text { = não, } 0 \text { = sim. }\end{array}$ \\
\hline & $\begin{array}{l}\text { Indicador de Práticas } \\
\text { de Preservação de } \\
\text { Recursos Ambientais } \\
\text { (IPRA) }\end{array}$ & $\begin{array}{l}\text { Usa cobertura vegetal permanente, faz pousio, conservação de } \\
\text { mata ciliar e reflorestamento (quando aplicável): (1 = sim, } \\
0 \text { = não; "não se aplica"). }\end{array}$ \\
\hline \multirow{6}{*}{ IATP } & \multirow{3}{*}{$\begin{array}{l}\text { Indicador Tecnologia } \\
\text { de Preparo do Solo } \\
\text { (ITPS) }\end{array}$} & Análise do solo: 1 = sim; 0 = não. \\
\hline & & Aração: 1 = sim; 0 = não. \\
\hline & & Gradagem cruzada: 2 = sim; 0 = não. \\
\hline & \multirow{3}{*}{$\begin{array}{l}\text { Indicador Tecnologia } \\
\text { de Sementes (ITS) }\end{array}$} & $\begin{array}{l}\text { Usa a variedade recomendada para o município: } 1 \text { = sim; } \\
0 \text { = não. }\end{array}$ \\
\hline & & $\begin{array}{l}\text { Fonte de sementes: grão semente }=0 \text {, própria selecionada ou } \\
\text { adquirida no comércio }=1 \text {; distribuída pelo Estado }=2 \text {. }\end{array}$ \\
\hline & & Tratamento das sementes com fungicidas: 1 = sim; 0 = não. \\
\hline
\end{tabular}


Quadro 1 - Continuação...

\begin{tabular}{|c|c|c|}
\hline Índices & Indicadores & Variáveis \\
\hline & $\begin{array}{l}\text { Indicador Tecnologia } \\
\text { de Plantio (ITP) }\end{array}$ & $\begin{array}{l}\text { Plantio manual = 0; plantio mecânico = 1; recomendação entre } \\
\text { covas (menor ou igual a } 40 \mathrm{~cm}=1 \text {, caso contrário }=0 \text { ); número } \\
\text { de sementes recomendadas (menor ou igual a } 3 \text { sementes }=1 \text {, } \\
0=\text { caso contrário); recomendação entre filas (entre } 50 \text { e } \\
100 \mathrm{~cm}=1 \text {; caso contrário }=0 \text { ). [Obs.: valores determinados } \\
\text { com base em Cruz et al., 2008]. }\end{array}$ \\
\hline & $\begin{array}{l}\text { Indicador Tecnologia } \\
\text { de Desbaste (ITD) }\end{array}$ & Realiza desbaste: 1 = sim; 0 = não. \\
\hline & \multirow{2}{*}{$\begin{array}{l}\text { Indicador Tecnologia } \\
\text { de Controle } \\
\text { Fitossanitário (ITCF) }\end{array}$} & $\begin{array}{l}\text { Não realiza }=0 ; \text { utiliza defensivo químico = } 1 \text {; utiliza controle } \\
\text { ecológico de pragas }=3 \text {. }\end{array}$ \\
\hline & & $\begin{array}{l}\text { Amplitude do controle: inseticida ( } 1=\operatorname{sim}, 0=\text { não); herbicida } \\
(1=\operatorname{sim}, 0=\text { não); e fungicida ( } 1=\operatorname{sim}, 0=\text { não). }\end{array}$ \\
\hline & $\begin{array}{l}\text { Indicador Tecnologia } \\
\text { de Pós-Colheita (ITPC) }\end{array}$ & $\begin{array}{l}\text { Baixo risco de armazenamento: } 1 \text { = sim, } 0 \text { = não (é } \\
\text { considerado baixo risco o armazenamento em recipiente } \\
\text { fechado, como tambores de plástico com tampas); usa } \\
\text { produto de controle de pragas no armazenamento: Gastoxim } \\
\text { ou pastilhas: } 2 \text { = sim; } 0 \text { = não. }\end{array}$ \\
\hline & \multirow{3}{*}{$\begin{array}{l}\text { Indicador dos Serviços } \\
\text { de Assistência técnica } \\
\text { (ISAT) }\end{array}$} & Recebe assistência técnica: 0 = não; 1 = sim. \\
\hline & & Forma de recebimento: 1 = em grupo; 2 = individual. \\
\hline & & $\begin{array}{l}\text { Frequência: } 1 \text { = mais de } 2 \text { meses; } 2 \text { = a cada } 2 \text { meses; } \\
3 \text { = mensalmente; } 4 \text { = a cada } 15 \text { dias. }\end{array}$ \\
\hline
\end{tabular}

Fonte: Adaptado de Passos (2014) e Silva (2005).

O Índice de Contribuição Econômica (ICE) objetiva mensurar a contribuição econômica da cultura do milho para a renda familiar e incorpora como única variável a Margem Bruta por hectare advinda da produção de milho. A Margem Bruta da produção de milho é definida pela Equação 3 (Hoffmann et al., 1978; Lampert, 2003):

$M B=R B T-C V$

Em que: RBT é a Renda Bruta Total obtida com a venda da produção de milho, somados os valores correspondentes ao autoconsumo e estoques; CV representa o custo variável da produção de milho, que inclui, além dos custos de mão-de-obra, custo da terra, sementes, fertilizantes, defensivos agrícolas, despesas com mecanização, colheita etc.

$\mathrm{Na}$ construção do IGAP, foram utilizadas as variáveis que aferem a adoção de práticas de conservação que reduzam o impacto ambiental da atividade agrícola. O IATP investiga o grau de adequação das práticas produtivas executadas pelos agricultores pesquisados avaliando os aspectos competitivos e tecnológicos da produção de milho híbrido (Cruz et al., 2008; Silva, 2005).

\subsection{Procedimentos metodológicos: aplicação das técnicas de Propensity Score Matching e Entropy Balancing}

Na avaliação dos impactos do Projeto Hora de Plantar, a técnica Propensity Score Matching foi executada nas seguintes etapas: estimação do modelo de escolha binária (Logit) e cálculo do escore de propensão; balanceamento por entropia conforme proposto por Watson \& Elliot (2016), pareamento dos grupos tratamento e controle; teste de balanceamento das variáveis e estimação do Efeito Médio do Tratamento sobre os Tratados (ATT) (Caliendo \& Kopeinig, 2005).

No Quadro 2, são descritas as covariáveis utilizadas para a definição do modelo de escolha binária. 
Quadro 2 - Variáveis determinantes da participação no Projeto Hora de Plantar

\begin{tabular}{|c|c|c|}
\hline Sigla & Descrição da Variável & Atribuição de Valores \\
\hline $\mathrm{P}$ & Variável dependente & 1 = beneficiários; 0 = não beneficiários. \\
\hline EC & Estado civil & 1 = com cônjuge; 0 = sem cônjuge. \\
\hline $\mathrm{CP}$ & $\begin{array}{l}\text { Condição do produtor } \\
\text { em relação à terra }\end{array}$ & 0 = cedido ou assentado; 1 = arrendatário; 2 = proprietário. \\
\hline $\mathrm{CM}$ & Condições de moradia & Própria $=1 ;$ alugada ou cedida $=0$ \\
\hline TA & $\begin{array}{l}\text { Tempo de trabalho na } \\
\text { agricultura }\end{array}$ & Menos de $5=0$, de 5 a $10=1 ;$ de 11 a $15=2$, mais de $15=3$ \\
\hline RTP & $\begin{array}{l}\text { Recebimento de } \\
\text { transferências públicas }\end{array}$ & $\begin{array}{l}\text { Não recebe }=0 \text {; somente Bolsa Família }=1 \text {; somente } \\
\text { aposentadoria ou pensão }=2 ; \text { Bolsa Família e } \\
\text { aposentadoria/pensão }=3 .\end{array}$ \\
\hline VTTP & $\begin{array}{l}\text { Valor total das } \\
\text { transferências públicas }\end{array}$ & Em reais \\
\hline APM & Área plantada de milho & Em hectares \\
\hline LOCAL & Dummy para localidades & $\begin{array}{l}\text { Atribuição de } 1 \text { para pertencente à localidade i e } 0 \text {, caso } \\
\text { contrário }\end{array}$ \\
\hline
\end{tabular}

Fonte: Elaboração própria.

Além das variáveis correspondentes ao perfil socioeconômico dos produtores e às características da área plantada, foram utilizadas dummies para localidade. Tais variáveis foram incluídas na análise visando captar, ainda que indiretamente, outros elementos passíveis de influenciar a atribuição do programa, como a produtividade dos solos da localidade, a articulação institucional da comunidade, o dinamismo econômico, a proximidade dos centros urbanos etc.

\subsection{Escolha do método de pareamento}

Existem diversas técnicas disponíveis (Becker \& Ichino, 2002; Khandker et al., 2010), como vizinho mais próximo (nearest neighbor - NN); pareamento radial (radius caliper - RC), Kernel e Regressão Local Linear (LLR).

O pareamento pelo vizinho mais próximo (NN) representa uma das técnicas mais utilizadas, que consiste no pareamento de uma observação no grupo tratamento com o seu correspondente no grupo controle que possua o escore de propensão mais próximo. Este tipo de pareamento pode fornecer pares pouco comparáveis se o escore de propensão das observações do grupo controle for muito distante do grupo tratamento. O método de pareamento radial (RC) propõe a imposição de um limite máximo de tolerância, como, por exemplo: se o escore de propensão de uma observação é de 0,65 , pode-se impor um raio de 0,05 e, assim, será pareado o vizinho mais próximo com escores de propensão entre 0,60 e 0,70 . Este método possui a vantagem de se reduzir o risco de pareamentos pobres, que surgem quando há um desequilíbrio entre as observações com escores de propensão alto e baixo entre os grupos tratamento e controle.

Os métodos descritos apresentam o risco de que apenas um pequeno subconjunto da amostra de não beneficiários possa satisfazer os critérios de pareamento de modo a permitir construir o resultado contrafactual. Assim, estimadores não paramétricos de pareamento, como Kernel e LLR, utilizam a média ponderada de todos os não beneficiários para construir um contrafactual para cada beneficiário.

\section{Resultados e Discussão}

\subsection{Estimação do modelo Logit}

A Tabela 1 discrimina os condicionantes da designação do tratamento e respectivos coeficientes do modelo Logit. 
Tabela 1 - Resultado do modelo Logit entre beneficiários do Projeto Hora de Plantar e não beneficiários, Microrregião do Cariri, 2015

\begin{tabular}{lcccc} 
& Odds Ratio & Coeficientes & $\mathbf{Z}$ & $\mathbf{p}>|\mathbf{z}|$ \\
CP (Condição do Produtor) & 0,230413 & $-1,467881$ & $-3,61$ & 0,000 \\
CM (Condição de Moradia) & 0,461036 & $-0,7742800$ & $-1,69$ & 0,090 \\
RTP (Recebimento de Transferências Públicas) & 2,103926 & 0,743805 & 2,10 & 0,036 \\
VTTP (Valor Total das Transferências Públicas) & 0,998616 & $-0,001385$ & $-2,96$ & 0,003 \\
TA (Tempo na Agricultura - faixa de 5 a 10 anos) & 5,347969 & 1,676717 & 3,24 & 0,001 \\
APM (Área plantada de milho) & 1,387183 & 0,3272754 & 1,68 & 0,093 \\
EC (Estado Civil) & 4,777828 & 1,563986 & 2,49 & 0,013 \\
Local - Brejo Grande & 1,834046 & 0,6065242 & 1,42 & 0,154 \\
Local - Latão & 2,627881 & 0,9661779 & 1,66 & 0,097 \\
Local - Santana & 16,63801 & 2,818169 & 3,85 & 0,000 \\
Constante & 4,657841 & 1,538552 & 1,51 & 0,132 \\
\hline
\end{tabular}

Fonte: Elaboração própria.

Conforme pode ser visualizado, no nível de 5\%, são significativos os coeficientes das variáveis referentes à condição do produtor, ao valor total das transferências públicas, ao tempo na agricultura na faixa de 5 a 10 anos e à variável dummy para a localidade de Santana (município de Barbalha) (Tabela 1). No nível de 10\%, somente não seria estatisticamente significativo o coeficiente da variável dummy para a localidade Brejo Grande (município de Santana do Cariri) (Tabela 1). Embora alguns valores dos coeficientes não tenham sido estatisticamente significativos no nível de 5\%, não significa necessariamente que tais variáveis devam ser excluídas do modelo. Rubin \& Thomas (1996) postulam que uma variável somente deve ser excluída se houver consenso de que esta não é apropriada.

A inclusão de variáveis de localidade, característica da propriedade, forma de acesso à terra, recebimento de transferências públicas e características do agricultor tem por finalidade tanto o cálculo da probabilidade de participação no programa quanto o pareamento das famílias de agricultores, em termos de características observáveis, de modo a gerar grupos mais homogêneos que sejam de fato comparáveis para a estimação do ATT.

A análise dos resultados revela que ser arrendatário reduz a probabilidade de participação no programa em $77 \%(C P=1)$ e ser proprietário da terra (CP = 2), em $94,6 \% 5$ (Tabela 1). Quanto à condição de moradia, ter casa própria $(C M=1)$ reduziria a chance de participação do programa em 53,9\%. O recebimento de transferência pública se relaciona de forma direta à chance de participação no programa. Uma possível explicação para esta evidência é que famílias que recebem transferências públicas apresentam geralmente menor renda familiar, sendo indício da maior focalização do programa em famílias de baixa renda.

Em relação ao tempo de trabalho na agricultura, somente apresentou significância estatística o coeficiente correspondente à faixa de tempo de 5 a 10 anos, com alto impacto sobre a chance de participação do programa (Tabela 1). Assim, para um agricultor que possua de 5 a 10 anos de trabalho, a probabilidade de participar do programa aumenta 434\%. Esta evidência pode estar relacionada ao fato de esses agricultores, em geral, se apresentarem ainda jovens para o trabalho agrícola e, desta forma, serem os que mais procuram o programa para recebimento de sementes híbridas. Outra possível explicação é que agricultores com maior tempo de agricultura e idade ainda reproduzem métodos tradicionais de cultivo de milho, optando pela seleção tradicional dos grãos e não pelas sementes híbridas.

A área plantada de milho também se relaciona diretamente à probabilidade de participação no Projeto Hora de Plantar.

\footnotetext{
${ }^{5}$ Os comentários têm como referência a odds ratio ("razão de chance"), ou seja, a razão entre a probabilidade de ser beneficiário e a probabilidade de não ser beneficiário.
} 
Quanto à variável referente ao estado civil, ser casado ou possuir companheiro(a) aumenta as chances de participar no programa em 377\% (Tabela 1). Isto possivelmente se deve ao fato de famílias constituídas possuírem uma dupla chance de participação no programa, pois o cadastro pode ser efetuado pelo homem ou mulher, inclusive pela possibilidade de transferência entre os cônjuges. Além disto, tais famílias representariam maior tendência à permanência no campo, o que poderia estar relacionado a algum padrão implícito de seleção para o programa.

O modelo estimado Logit, cujos resultados encontram-se na Tabela 1, apresentou um bom ajuste, com percentual de $72,4 \%$ de casos corretamente classificados, possibilitando a obtenção dos escores de pareamento necessários às etapas seguintes da técnica.

\subsection{Análise do Balanceamento das covariáveis e escolha dos métodos de pareamento}

Após a definição e estimação do modelo Logit, obtiveram-se como resultado os escores de propensão para cada indivíduo, dos grupos tratamento e controle. No âmbito deste artigo, optou-se por comparar os resultados obtidos mediante o pareamento por escore de propensão, antes e depois da aplicação do balanceamento por entropia das covariáveis, de modo a identificar as vantagens da aplicação dessa técnica. Há diversas técnicas de pareamento disponíveis, como vizinho mais próximo (nearest-neighbor matching); radial (caliper and radius matching); método de Kernel e local linear. A literatura sobre o tema não aponta qual o melhor método, sendo recomendável que se tentem várias abordagens. Assim, optou-se por comparar os resultados utilizando o método de pareamento do vizinho mais próximo, por ter fornecido, em estimativas preliminares, o maior nível de redução do viés após o pareamento.

A utilização da técnica de propensity score matching permite a construção de um grupo controle (contrafactual) a partir da estimativa do escore de propensão. Ocorre, porém, que um grupo contrafactual adequado deve ter, em média, as mesmas características do grupo tratamento, de modo que a designação de tratamentos entre indivíduos com base no vetor de covariáveis observáveis $X$ seja aleatória. Tal condição é vital para um pareamento adequado (Diprete \& Gangl, 2004; Rosenbaum \& Rubin, 1983). Portanto, a análise do balanceamento das covariáveis entre os grupos tratamento e controle foi efetuada a partir dos seguintes parâmetros: a) nível de significância do teste t para média entre tratados e não tratados após o pareamento, e b) nível de redução do viés após o pareamento. O nível de significância do teste t representa um parâmetro intuitivamente claro do nível de balanceamento, em que um bom balanceamento deve permitir aceitar a hipótese nula do teste de que as médias das covariáveis entre os grupos após o pareamento não são distintas. A análise do percentual de redução do viés, além de indicar potencialmente os métodos mais eficazes na formação de grupos homogêneos, fornece informações sobre as variáveis em que a heterogeneidade ainda prevalece, subsidiando a análise, de modo a reforçar ou relativizar as conclusões advindas dos dados empíricos.

$\mathrm{Na}$ análise anterior ao balanceamento por entropia, procedeu-se à avaliação do balanceamento das covariáveis para os quatro principais métodos de pareamento: Kernel, vizinho mais próximo (nearest neighbor - NN); pareamento radial (radius caliper - RC) e Regressão Local Linear (LLR), cujos resultados encontram-se na Tabela 2.

Tabela 2 - Parâmetros para avaliação do balanceamento de covariáveis, por métodos de pareamento, Microrregião do Cariri, 2015

\begin{tabular}{lcccc}
\multicolumn{1}{c}{ Parâmetros para Avaliação do Balanceamento } & Kernel & NN & RC & LLR \\
Nível de significância - estatística LR & 0,761 & 0,685 & 0,763 & 0,902 \\
Pseudo - R & 0,028 & 0,031 & 0,028 & 0,023 \\
Covariáveis que apresentaram razão de variância & APM e CM & APM & APM & APM \\
[V(T)/V(C)] estatisticamente diferente da unidade & 10,9 & 7,4 & 10,8 & 8,8 \\
\% viés médio para covariáveis após pareamento & 12.0 & &
\end{tabular}

Fonte: Elaboração própria com a utilização do software Stata versão 12.0 
O pareamento pelo método do vizinho mais próximo (NN) apresentou o melhor ajustamento com viés médio após o pareamento em torno de 7,4\% (Tabela 2), sendo o método de pareamento escolhido. Além do viés médio remanescente após o pareamento, o modelo estimado apresentou valores do nível de significância para a estatística LR e Pseudo- $R^{2}$, de 0,685 e 0,031, respectivamente (Tabela 2). Assim, os dados obtidos denotam que o nível de significância da estatística LR permite aceitar a hipótese de nulidade conjunta dos coeficientes para todos os métodos de pareamento. Tal evidência é corroborada pelos baixos valores do Pseudo- $\mathrm{R}^{2}$, o que é de se esperar no caso de a atribuição do tratamento ser aleatória.

Ressalta-se que, apesar da significativa redução do viés após o pareamento, ainda permanece a disparidade entre o grupo tratamento e o grupo controle em relação aos valores médios de algumas variáveis. Embora as disparidades encontradas sejam pequenas e permitam a comparação entre os grupos beneficiários e não beneficiários do Projeto Hora de Plantar pelo método convencional de PSM, a existência de viés remanescente reduz a robustez das conclusões.

A Tabela 3 apresenta os resultados do balanceamento por entropia das covariáveis preditoras da participação do Projeto Hora de Plantar.

Tabela 3 - Comparação entre a distribuição estatística das covariáveis antes e depois do balanceamento por entropia, Microrregião do Cariri, 2015

\begin{tabular}{|c|c|c|c|c|c|c|}
\hline \multirow{2}{*}{ Covariáveis } & \multicolumn{3}{|c|}{ Diferença antes balanceamento } & \multicolumn{3}{|c|}{ Diferença após balanceamento } \\
\hline & Média & Variância & Assimetria & Média & Variância & Assimetria \\
\hline $\begin{array}{l}\text { Condição do produtor em } \\
\text { relação à terra }\end{array}$ & $-0,158$ & 0,110 & 0,012 & 0,000 & 0,121 & 0,701 \\
\hline Condições de moradia & $-0,066$ & 0,133 & 1,509 & 0,000 & 0,028 & $-0,076$ \\
\hline $\begin{array}{l}\text { Recebimento de } \\
\text { transferências públicas }\end{array}$ & $-0,044$ & $-0,023$ & 0,328 & 0,000 & $-0,012$ & $-0,095$ \\
\hline $\begin{array}{l}\text { Tempo de trabalho na } \\
\text { agricultura }\end{array}$ & 0,167 & 0,118 & $-2,213$ & 0,000 & 0,001 & 0,000 \\
\hline $\begin{array}{l}\text { Área plantada de milho (em } \\
\text { hectares) }\end{array}$ & 0,226 & 0,787 & 1,084 & 0,000 & 0,666 & 1,759 \\
\hline $\begin{array}{l}\text { Valor total das } \\
\text { transferências públicas }\end{array}$ & $-191,3$ & -200726 & 0,395 & 0,000 & -43579 & $-0,070$ \\
\hline Estado civil & $-0,086$ & $-0,070$ & 1,826 & 0,000 & 0,000 & 0,001 \\
\hline Local - Brejo Grande & $-0,033$ & $-0,021$ & 0,289 & 0,000 & 0,000 & 0,000 \\
\hline Local - Latão & 0,075 & 0,062 & $-1,612$ & 0,000 & 0,000 & 0,000 \\
\hline Local - Santana & 0,114 & 0,093 & $-2,686$ & 0,000 & 0,000 & 0,000 \\
\hline
\end{tabular}

Fonte: Elaboração própria.

O balanceamento foi obtido para a média. Apesar de não se obter a convergência de valores para momentos de ordem superiores, percebe-se significativa redução da disparidade entre os grupos, em relação a variância e assimetria, para a maioria das covariáveis.

O Gráfico 1 mostra a distribuição dos escores de propensão antes e depois do balanceamento por entropia. Em azul, estão os valores do escore de propensão do grupo tratamento e, em vermelho, os valores dos escores de tratamento do grupo controle. 

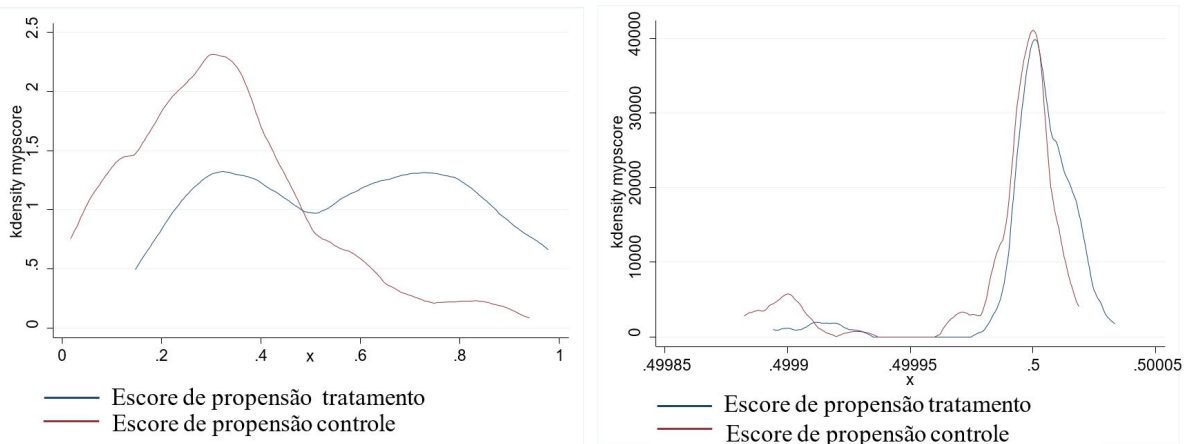

Gráfico 1. Distribuição dos escores de propensão, por grupo, antes e depois do balanceamento por entropia. Fonte: Elaboração própria.

No gráfico à esquerda, antes do balanceamento, percebe-se a elevada dispersão dos escores de propensão entre os grupos tratamento e controle, com o grupo controle apresentando concentração de observações nos menores escores (Gráfico 1). Após o balanceamento, identifica-se nitidamente a homogeneidade entre os grupos, não apenas pela similaridade entre as distribuições dos escores, mas também pela escala, com variação de valores para a propensão ao tratamento entre $49,9 \%$ e $50 \%$, significando que os dois grupos são tão homogêneos que a atribuição ao tratamento se apresenta aleatória (Gráfico 1).

\subsection{Análise do impacto do Projeto Hora de Plantar na sustentabilidade dos produtores de milho híbrido}

O ATT representa o efeito médio do tratamento sobre os tratados (beneficiários) e é negativo ou positivo, indicando o impacto negativo ou positivo do programa em relação às variáveis de resultado. Nesta pesquisa, a variável resultado principal é o Índice de Sustentabilidade da Produção (ISP), porém foi estimado, de forma adicional, o efeito do ATT para os índices e indicadores componentes do ISP. Os desvios padrões das estimativas do ATT foram corrigidos pela técnica de bootstrapping com 400 replicações, seguindo recomendações de Andrews \& Buchinsky (2000).

$\mathrm{Na}$ Tabela 4, são apresentadas as estimativas para o efeito do tratamento sobre os Tratados (ATT) após o balanceamento das covariáveis e utilizando o método de pareamento pelo vizinho mais próximo.

Tabela 4 - Efeito do Tratamento sobre os Tratados (ATT) através de pareamento por escore de propensão, por métodos de pareamento e variáveis de interesse, Microrregião do Cariri, 2015

\begin{tabular}{cccccccc}
$\begin{array}{c}\text { Indicadores e } \\
\text { Índices }\end{array}$ & Controle Tratamento & ATT & $\begin{array}{c}\text { Indicadores e } \\
\text { Índices }\end{array}$ & Controle Tratamento & ATT \\
(ICE) & 0,2192 & 0,3326 & $0,1134 * * *$ & (IATP) & 0,3124 & 0,4309 & $0,1185^{* * *}$ \\
MBHEC & 824,7 & 1363,69 & $538,99 * * *$ & (ITPS) & 0,3232 & 0,2744 & $-0,0488^{* *}$ \\
(IGAP) & 0,3979 & 0,3809 & $-0,017$ & (ITS) & 0,1707 & 0,6439 & $0,4732^{* * *}$ \\
(IPAPS) & 0,75 & 0,6037 & $-0,1463$ & (ITP) & 0,3872 & 0,5487 & $0,1615^{* *}$ \\
(IPPA) & 0,2029 & 0,1992 & $-0,0037$ & (ITD) & 0,4634 & 0,4878 & 0,0244 \\
(IPPP) & 0,6707 & 0,6951 & 0,0244 & (ITCF) & 0,439 & 0,4268 & $-0,0122$ \\
(IPRA) & 0,2764 & 0,3211 & 0,0447 & (ITPC) & 0,3109 & 0,4938 & 0,1829 \\
(IPCP) & 0,4146 & 0,4055 & $-0,0091$ & (ISAT) & 0,0923 & 0,141 & 0,0487 \\
(IGRS) & 0,0732 & 0,061 & $-0,0122$ & (ISP) & 0,2914 & 0,3812 & $0,0898 * * *$ \\
\hline
\end{tabular}

Nota: Estimativas dos desvios padrões corrigidas pelo método de bootstrapping; $\left({ }^{* *}\right)$ - denota nível de significância inferior a 1\%; $\left(^{* *}\right)$ - denota nível de significância inferior a 5\%; $\left(^{*}\right)$ - denota nível de significância inferior a $10 \%$. Fonte: Elaboração própria. 
A análise do ICE indica estimativas em torno de $52 \%$ superiores para o grupo tratamento em comparação ao grupo controle. Para o indicador margem bruta do milho por hectare, os beneficiários do projeto analisado apresentaram uma diferença percentual em torno de $65 \%$ em relação aos não beneficiários. Essa inferência está em acordo com resultados de Silva et al. (2006), que também encontraram significativa diferença entre produtividade e rentabilidade dos produtores de milho híbrido em comparação aos produtores de milho variedade, no estado do Ceará De posse destes resultados, podem-se estimar os benefícios sociais e a viabilidade econômica do Projeto Hora de Plantar. Tomando-se a estimativa mais conservadora do Efeito Médio do Tratamento entre os Tratados (ATT) de R\$538,99 por hectare, juntamente com o número de beneficiários com a distribuição de sementes de milho híbrido para o ano de 2015, que foi de 75.888 produtores e uma média de cerca de 29,4 kg de sementes por produtor (o que permite um plantio de 1,47 hectares), tem-se que o diferencial de renda gerada para o conjunto dos agricultores beneficiários de milho híbrido foi de 40,9 milhões de reais, o que representa cerca de duas vezes o orçamento total do projeto. Tal evidência corrobora o efeito positivo do Projeto Hora de Plantar sobre a renda bruta familiar devido ao aumento da produção. Todos os coeficientes do ATT foram positivos e estatisticamente significativos no nível de $1 \%$.

A análise do Índice de Adoção Tecnológica da Produção (IATP) evidencia a presença de valores positivos para o ATT. Tal efeito mostrou-se estatisticamente significativo no nível de 1\%. Em termos de magnitude da diferença entre beneficiários e não beneficiários, o valor para a estimativa do ATT obtido foi em torno de $38 \%$ a favor dos beneficiários do programa. Além do IATP, apenas o Indicador Tecnologia de Sementes (ITS) apresenta estimativas significativas a $1 \%$, sendo o indicador que apresentou a maior diferença percentual entre os dois grupos. O Indicador Tecnologia de Plantio (ITP) aponta efeitos positivos para o ATT e significantes no nível de 5\%. Tais resultados implicam na maior tendência de plantio mecanizado entre os agricultores pertencentes ao grupo tratamento, consequentemente possibilitando menor espaçamento entre o plantio e maior produção e renda por hectare (Cruz et al., 2008; Silva et al., 2006). Assim, pelos resultados da Tabela 4, percebe-se que a utilização de sementes híbridas e a maior tendência ao plantio mecanizado respondem pela maior parcela da diferença entre os níveis tecnológicos observados entre os grupos.

É necessário ressaltar que a maioria dos indicadores da dimensão tecnológica apresentou diferença positiva entre os grupos, indicando que a média para o grupo tratamento superou a média para o grupo controle após o pareamento; porém, apesar de essas diferenças serem estatisticamente não significativas para a maioria dos indicadores, 0 efeito conjunto expresso no IATP mostrou-se estatisticamente significativo. Há de se considerar o elevado peso do Indicador Tecnologia de Sementes no IATP, representando tal medida a principal responsável pelas diferenças entre os grupos tratamento e controle. Assim, apesar da evidência de diferenças significativas entre os grupos, estas parecem estar fortemente influenciadas por apenas um indicador. Ademais, os baixos níveis de Serviços de Assistência técnica para os dois grupos pesquisados sugerem uma limitação do projeto no que diz respeito ao estímulo da adoção de práticas agrícolas tecnologicamente mais adequadas, o que restringe as perspectivas de aumento da produtividade e geração de renda agrícola - determinado basicamente pela inovação tecnológica nas sementes distribuídas -, podendo estar correlacionado ainda ao desempenho da dimensão ambiental.

A análise do Índice de Gestão Ambiental da Propriedade (IGAP) revela que os dois grupos possuem baixo nível de sustentabilidade ambiental. Os indicadores que evidenciaram práticas de maior pressão sobre o meio ambiente foram IPPA, IPRA e IGRS, o que revela a pouca preocupação dos dois grupos com formas alternativas de adubação, preservação dos recursos naturais e má gestão dos resíduos sólidos gerados, sobretudo, em relação ao destino inadequado de embalagens dos defensivos agrícolas, em que $74 \%$ descartam de forma irregular. Portanto, tornam-se necessárias ações de educação ambiental para os dois grupos.

Além disto, os resultados do IGAP evidenciam efeito negativo para o ATT, porém, apesar de nenhum dos coeficientes, tanto do IGAP quanto dos indicadores que o compõem, serem estatisticamente significativos, a presença de sinal negativo no IPAPS indica maior tendência entre os beneficiários de praticar desmatamento e queimadas, representando tal indicador, 
em virtude da expressiva magnitude relativa, o componente de maior peso no índice da dimensão ambiental. A não significância estatística dos coeficientes estimados implica na inexistência de diferença entre os grupos em relação à utilização de práticas agrícolas de menor impacto ambiental. Há de se ressaltar que o estímulo à adoção de tais práticas constitui um dos objetivos específicos do Projeto Hora de Plantar, estando previsto inclusive incentivo financeiro para o produtor que as adotar; porém, as informações da pesquisa de campo indicam que os agricultores desconhecem este incentivo. Além disto, há a possibilidade de o bônus concedido sob a forma de abatimentos na contrapartida das sementes por parte do beneficiário ser, em virtude do reduzido valor, incapaz de promover a transformação de práticas de cultivo culturalmente enraizadas.

Em relação ao Índice de Sustentabilidade da Produção (ISP), o método de pareamento forneceu estimativas positivas para o ATT e estatisticamente significativas no nível de $1 \%$. As diferenças percentuais entre os grupos tratamento e controle ficaram em torno de $31 \%$ a favor do grupo tratamento. Tais diferenças são determinadas predominantemente pelas dimensões econômica e tecnológica, e indicam que os agricultores beneficiários do Projeto Hora de Plantar apresentaram, em média, maior nível de sustentabilidade da produção em relação aos agricultores familiares não participantes do projeto.

\section{Conclusões}

No que concerne à utilização da técnica de Propensity Score Matching, combinada com a técnica de balanceamento por entropia, para identificar o efeito do Projeto Hora de Plantar sobre os produtores de milho híbrido da Microrregião do Cariri, pode-se afirmar o êxito na obtenção de grupos homogêneos em relação às variáveis preditoras da designação do tratamento, representando condição essencial para a validade estatística das diferenças observadas entre os beneficiários e não beneficiários do programa. Há de se destacar que, apesar de as estimativas preliminares obtidas com a implementação do método PSM convencional terem se mostrado satisfatórias em relação à significativa redução do viés entre os grupos, o balanceamento por entropia obteve grupos mais homogêneos permitindo ganho significativo de robustez dos resultados e conclusões deste trabalho.

Em relação à contribuição econômica, os resultados evidenciaram que os participantes do programa apresentaram expressivos e estatisticamente significativos diferenciais de renda devido ao aumento da produção, corroborando um nítido efeito do Programa Hora de Plantar sobre o nível de renda dos beneficiários.

Em relação à Gestão Ambiental da Propriedade, os resultados estimados indicam que os efeitos do programa são estatisticamente não significativos, o que denota a não obtenção de sucesso do programa na consecução do importante objetivo que se refere à adoção de práticas ambientais conservacionistas e de convivência com o semiárido. De modo geral, os agricultores pesquisados possuem baixo nível de consciência ambiental, espelhada pela não adoção de técnicas ambientalmente menos impactantes. A não adoção generalizada destas técnicas, e, na maioria dos casos (conforme relatos em campo), o completo desconhecimento por parte destes produtores sugerem uma deficiência nos trabalhos de extensão tecnológica em nível estadual, cuja investigação foge ao escopo desta pesquisa.

Em relação ao nível tecnológico dos produtores, a informação colhida por diferentes indicadores aponta para a perpetuação de um baixo nível tecnológico, em que as práticas produtivas convencionais relacionadas à cultura do milho são ignoradas pela maior parte dos agricultores. O resultado deste último elemento é a manutenção de níveis de produtividade extremamente baixos para a maioria dos produtores, sobretudo para os não beneficiários do programa com reflexo na renda da atividade, inviabilizando em parte a capacidade de geração de renda da agricultura familiar, perpetuando o quadro de pobreza e baixo nível de dinamismo econômico deste segmento.

De modo geral, os dois grupos de produtores apresentaram baixo nível de sustentabilidade da produção, porém com maior concentração de produtores não beneficiários nos valores inferiores à média do índice. A partir dos dados mostrados, o que se percebe é que, para um número significativo de produtores, a questão ambiental continua distante e marcadamente ausente de atitudes concretas tanto em nível pessoal como 
coletivo, e a prática produtiva mantém-se resistente à incorporação de técnicas simples de manutenção da fertilidade do solo e aumento da produtividade. Obviamente, os elementos explicativos da manutenção de níveis tão baixos de sustentabilidade demandam investigações mais específicas que contemplem tanto a atuação das políticas públicas voltadas ao homem do campo quanto a eficiência de ações de promoção da sustentabilidade da produção e da renovação de uma agricultura, no sentido de convivência mais harmônica com as condições do semiárido.

Assim, o impacto mais significativo do programa em termos de magnitude das diferenças entre os dois grupos deu-se apenas no aspecto econômico. No âmbito tecnológico, a magnitude das diferenças estimadas foi menor, com forte influência do Indicador Tecnologia de Sementes, e menor importância dos demais indicadores do índice de Adequação Tecnológica da Produção.

Todavia, a maior fragilidade do Projeto Hora de Plantar é identificada em relação à dimensão ambiental, pois se percebe que o referido programa elenca como objetivos não apenas a substituição de plantio de grãos por sementes de alta qualidade genética, mas também a adoção de práticas agrícolas de convivência com o semiárido, concedendo inclusive incentivo financeiro - na forma de redução no pagamento das sementes - para os produtores que adotam práticas ambientais menos impactantes. O Programa Hora de Plantar, porém, não prevê ações para a consecução deste objetivo. A realidade empírica revelou o desconhecimento de tais incentivos pelo produtor e reforça a hipótese da existência de uma deficiência, por parte dos gestores, tanto da transmissão da informação do programa para estes produtores quanto da difusão das mencionadas tecnologias. Obviamente, não se pode impor apenas aos órgãos de Assistência Técnica e Extensão Rural toda a responsabilidade pelo baixo nível tecnológico dos produtores cearenses, pois tal analogia simplista ignora o caráter multifacetado das limitações à adoção de novas práticas produtivas pelo pequeno agricultor familiar.

Um questionamento recorrente em avaliação de políticas públicas diz respeito aos benefícios sociais e custos econômicos da atuação governamental. Neste sentido, os resultados obtidos para o Efeito Médio do Tratamento sobre os Tratados (ATT) para a margem bruta obtida pelos beneficiários sugerem que os benefícios sociais superam com largas vantagens os custos econômicos do projeto, sendo o subsídio na forma de distribuição de sementes híbridas preferível à transferência de renda direta ao produtor (no valor orçado para o programa), por gerar maior renda final ao beneficiário. Entretanto, conforme abordado, os efeitos mais significativos do programa estão restritos à dimensão econômica. Neste sentido, recomenda-se aos gestores do Projeto Hora de Plantar a incorporação, nas ações previstas para o programa, da ampliação dos serviços de assistência técnica e extensão rural, via maior frequência das visitas in loco e reuniões de conscientização e formação para o estímulo à adoção de práticas agrícolas sustentáveis.

\section{Referências}

Almeida, J. (1998). Significados sociais, desafios e potencialidades da agroecologia. In A. D. Ferreira \& A. Brandenburg (Eds.), Para pensar outra agricultura (pp. 239-247). Curitiba: UFPR.

Altieri, M. (2000). Agroecologia: a dinâmica produtiva da agricultura sustentável (110 p.). Porto Alegre: UFRGS.

Andrews, D. W. K., \& Buchinsky, M. Y. (2000). On the number of bootstrap repetitions for BC a confidence intervals (Discussion Papers, No. 1250). Yale: Yale University.

Attanasio, O., Battistin, E., Fitzsimons, E., Mesnard, A., \& Vera-Hernandez, M. (2005). How effective are conditional cash transfers? Evidence from Colombia (Briefing Note, No. 54). London: The Institute for Fiscal Studies. Recuperado em 5 de março de 2011, de http://www.ifs.org.uk/publications.php

Barreto, R. C. S., Khan, A. S., \& Lima, P. V. P. S. (2005). Sustentabilidade dos assentamentos no município de Caucaia-CE. Revista de Economia e Sociologia Rural, 43(2), 225-247. http://dx.doi.org/10.1590/S0103-20032005000200002

Becker, S. O., \& Ichino, A. (2002). Estimation of average treatment effects based on propensity scores. The Stata Journal, 2(4), 358-377. http://dx.doi.org/10.1177/1536867X0200200403 
Bertocchi, M., Demartini, E., \& Marescotti, M. E. (2016). Ranking farms using quantitative indicators of sustainability: the 4Agro method. Procedia: Social and Behavioral Sciences, 223, 726-732. http://dx.doi.org/10.1016/j.sbspro.2016.05.249

Bursztyn, M., \& Bursztyn, M. A. A. (2010). Sustentabilidade, ação pública e meio rural no Brasil: uma contribuição ao debate. Raízes, 29(1-2), 10-18.

Caliendo, M., \& Kopeinig, S. (2005). Some practical guidance for the implementation of propensity score matching (Discussion Paper, No. 1588). Bonn, Germany: Institute for the Study of Labor. Recuperado em 13 de fevereiro de 2014, de http://ftp.iza.org/dp1588.pdf

Caporal, F. R., \& Costabeber, J. A. (2004). Agroecologia e extensão rural: contribuições para a promoção do desenvolvimento rural sustentável (166 p.). Brasília: MDA/SAF/DATER-IICA.

Ceará. Secretaria de Desenvolvimento Agrário. (2015). Projeto Hora de Plantar XXVIII: manual operacional 2015 (105 p.). Fortaleza: SDA.

Ceará. Secretaria de Desenvolvimento Agrário. (2016). Cédula de Agricultura Familiar - CODAF. Fortaleza: SDA.

Cochran, W. (1985). Sampling tecniques (2nd ed.). Boston: John Wiley \& Sons.

Cruz, J. C., Karam, D., Monteiro, M. A. R., \& Magalhães, P. C. (Eds.). (2008). A cultura do milho (517 p.). Sete Lagoas: Embrapa Milho e Sorgo.

Cuenca, M. A. G., Nazário, C. C., \& Mandarino, D. G. (2005). Aspectos agroeconômicos da cultura do milho: características e evolução da cultura no estado do Ceará entre 1990 e 2003 (Documentos, No. 82, 28 p.). Aracaju: Embrapa Tabuleiros Costeiros.

Damasceno, N. P., Khan, A. S., \& Lima, P. V. P. S. (2011). O impacto do Pronaf sobre a sustentabilidade da agricultura familiar, geração de emprego e renda no Estado do Ceará. Revista de Economia e Sociologia Rural, 49(1), 129-156.

Diamond, A., \& Sekhon, J. S. (2013). Genetic matching for estimating causal effects: a general multivariate matching method for achieving balance in observational studies. The Review of Economics and Statistics, 95(3), 932-945.

Diprete, T., \& Gangl, M. (2004). Assessing bias in the estimation of causal effects: Rosenbaum bounds on matching estimators and instrumental variables estimation with imperfect instruments. Sociological Methodology, 34(1), 271-310. http://dx.doi.org/10.1111/j.0081-1750.2004.00154.x

Duarte, G. B., Sampaio, B., \& Sampaio, Y. (2009). Programa Bolsa Família: impacto das transferências sobre os gastos com alimentos em famílias rurais. Revista de Economia e Sociologia Rural, 47(4), 903918.

Duarte, S. P. S. (2017). Efeitos do programa Agroamigo sobre os pequenos produtores rurais do Cariri cearense (Dissertação de mestrado). Centro de Ciências Agrárias, Universidade Federal do Ceará, Fortaleza, .

Empresa Brasileira de Pesquisa Agropecuária - EMBRAPA. (2018). Visão 2030: o futuro da agricultura brasileira. Brasília: EMBRAPA.

Ferreira, L. C. (1998). A questão ambiental: sustentabilidade e políticas públicas no Brasil (154p.). São Paulo: Boitempo Editorial.

Fundação Cearense de Meteorologia e Recursos Hídricos - FUNCEME. Secretaria de Recursos Hídricos. (2015). Base de Dados: Calendário das Chuvas. Recuperado em 10 de dezembro de 2015, de <http://www.funceme.br/app/calendario/produto/municipios/maxima/diario?data=hoje

Gliessman, S. R. (2000). Agroecologia: processos ecológicos em agricultura sustentável (653р.). Porto Alegre: UFRGS.

Grisa, C., \& Schneider, S. (2014). Três gerações de políticas públicas para a agricultura familiar e formas de interação entre sociedade e estado no Brasil. Revista de Economia e Sociologia Rural, 52(Supl. 1), 125-146.

Hainmueller, J. (2012). Entropy balancing for causal effects: a multivariate reweighting method to produce balanced samples in observational studies. Political Analysis, 20(1), 25-46.

Hălbac-Cotoară-Zamfir, R., Keesstra, S., \& Kalantari, Z. (2019). The impact of political, socio-economic and cultural factors on implementing environment friendly techniques for sustainable land management and climate change mitigation in Romania. The Science of the Total Environment, 654 418-429.

Hayati, D., Ranjbar, Z., \& Karami, E. (2011). Measuring agricultural sustainability. In E. Lichtfouse (Ed.), Biodiversity, biofuels, agroforestry and conservation agriculture (Sustainable Agriculture Reviews, No. 5, pp. 73-100). Netherlands: Springer. http://dx.doi.org/10.1007/978-90-481-9513-8_2. 
Heckman, J. J., Lalonde, R., \& Smith, J. (1999). The economics and econometrics of active labor market programs. In O. Ashenfelter \& D. Card (Eds.), Handbook of labor economics (Vol. 3, pp. 1865-2097). Amsterdam: Elsevier.

Hirano, K., Imbens, G., \& Ridder, G. (2003). Efficient estimation of average treatment effects using the estimated propensity score. Econometrica, 71(4), 1161-1189. http://dx.doi.org/10.1111/14680262.00442

Hoffmann, R., Engler, J. J. C., Serrano, O., Thame, A. C. M., \& Neves, E. M. (1978). Administração da empresa agrícola. São Paulo: Pioneira.

Imbens, G. (2000). A role of the propensity score in estimating Dose-Response functions. Biometrika, 87(3), 706-710.

Instituto Brasileiro de Geografia e Estatística - IBGE. (2009). Censo agropecuário 2006: agricultura familiar: primeiros resultados: Brasil, grandes regiões e unidades da federação (267 p.). Rio de Janeiro: IBGE. Recuperado em 10 de março de 2013, de http://biblioteca.ibge.gov.br/visualizacao/periodicos/50/agro_2006_agricultura_familiar.pdf

Instituto Brasileiro de Geografia e Estatística - IBGE. (2015). Produção agrícola municipal - 2014. Rio de Janeiro: IBGE.

Instituto de Pesquisa e Estratégia Econômica do Ceará - IPECE. (2010). Ceará em mapas - 2010. Fortaleza: IPECE. Recuperado em 10 de junho de 2011, de http:www2.ipece.ce.gov.br/ atlas/

Khandker, S. R., Koolwal, G. B., \& Samad, H. A. (2010). Handbook on impact evaluation: quantitative methods and practices. Washington: The International Bank of Reconstruction and Development/The Word Bank. Recuperado em 10 de dezembro de 2014, de https://openknowledge.worldbank.org/bitstream/handle/10986/2693/520990PUB0EPI1101Official0 Use0Only1.pdf?sequence=1

Kullback, S. (1959). Information theory and statistics. New York: Wiley.

Labrador Moreno, J., \& Altieri, M. A. (1994). Manejo y diseño de sistemas agrícolas sustentables. Hoja Divulgadora, (6-7), 1-52.

Lampert, J. A. (2003). Administração rural (Caderno didático de administração rural). Santa Maria: DEAER/UFSM.

Leff, E. (2009). Ecologia, capital e cultura: a territorialização da racionalidade ambiental (1. ed., 440 p.). Petrópolis: Vozes.

Lopes, S. B. (2001). Arranjos institucionais e a sustentabilidade de sistemas agroflorestais: uma proposição metodológica (Dissertação de mestrado). Universidade Federal do Rio Grande do Sul, Porto Alegre.

Olde, E. M., Moller, H., Marchand, F., McDowell, R. W., MacLeod, C. J., Sautier, M., Halloy, S., Barber, A., Benge, J., Bockstaller, C., Bokkers, E. A. M., de Boer, I. J. M., Legun, K. A., Le Quellec, I., Merfield, C., Oudshoorn, F. W., Reid, J., Schader, C., Szymanski, E., Sørensen, C. A. G., Whitehead, J., \& Manhire, J. (2017). When experts disagree: the need to rethink indicator selection for assessing sustainability of agriculture. Environment, Development and Sustainability, 19(4), 1327-1342.

Passos, A. T. B. (2014). O impacto do PRONAF SUSTENTÁVEL sobre a sustentabilidade agrícola da agricultura familiar: o caso da microrregião do Vale do Médio Curu no Estado do Ceará (Tese de doutorado). Universidade Federal do Ceará, Fortaleza.

Rodrigues, A. M. (2009). A abordagem ambiental: questões para reflexão. GeoTextos, 5(1), 183-201.

Rosenbaum, P. R., \& Rubin, D. (1983). The central role of the propensity score in observational studies for causal effects. Biometrika, 70(1), 41-55.

Rubin, D. B., \& Thomas, N. (1996). Matching using estimated propensity scores: relating theory to practice. Biometrics, 52(1), 249-264.

Sambuichi, R. H. R., Oliveira, M. A. C., Silva, A. P. M., \& Luedemann, G. (2012). A sustentabilidade ambiental da agropecuária brasileira: impactos, políticas públicas e desafios (Texto para Discussão, No. 1782). Brasília: IPEA. Recuperado em 16 de maio de 2016, de http://repositorio.ipea.gov.br/bitstream/11058/ 1050/1/TD_1782.pdf

Santana, C. S., Folhes, M. T., Mayorga, R. D., \& Mayorga, M. I. (1999). O Programa Hora de Plantar sob a ótica dos agricultores beneficiados no estado do Ceará. In M. N. Barradas (Ed.), Desenvolvimento sustentável em busca da operacionalização (1. ed., Vol. 1, pp. 89-98). Fortaleza: Universidade Federal do Ceará.

Santos, J. G., \& Cândido, G. A. (2013). Sustentabilidade e agricultura familiar: um estudo de caso em uma associação de agricultores rurais. Revista de Gestão Social e Ambiental, 7(1), 70-83. 
Silva, D. M. F. (2005). Avaliação do programa do milho híbrido no Estado do Ceará: aspectos competitivos, tecnológicos e seus determinantes, geração de emprego e renda (Dissertação de mestrado). Universidade Federal do Ceará, Fortaleza.

Silva, D., Khan, A. S., \& Lima, P. V. P. S. (2006). Produção de milho híbrido no Estado do Ceará: aspectos tecnológicos, competitivos, geração de emprego e renda. Revista de Economia e Sociologia Rural, 44(1), 119-146.

Trevisan, A. P., \& Van Bellen, H. M. (2008). Avaliação de políticas públicas: uma revisão teórica de um campo em construção. Revista de Administração Pública, 42(3), 529-550.

Watson, S., \& Elliot, M. (2016). Entropy balancing: a maximum-entropy reweighting scheme to adjust for coverage error. Quality \& Quantity, 50(4), 1781-1797.

Zhang, T. Q., Zheng, Z. M., Lal, R., Lin, Z. Q., Sharpley, A. N., Shober, A. L., Smith, D., Tan, C. S., \& Van Cappellen, P. (2018). Environmental indicator principium with case references to agricultural soil, water, and air quality and model-derived indicators. Journal of Environmental Quality, 47(2), 191-202.

Submetido 3/Maio/2018

Aceito: 21/Abr./2019

JEL Classification: C14, Q18 